\title{
Psicanálise e Ética: um trilhamento pela mensagem freudiana ${ }^{1}$ Psychoanalysis and Ethics: a tracking through the Freudian message
}

\author{
RICARDO JOSÉ PERIN ${ }^{2}$
}

\begin{abstract}
Resumo: Neste artigo, visa-se estabelecer uma interlocução entre ética e psicanálise, partindo da temática apresentada na edição especial da Revista Francesa de Psicanálise. Com o objetivo de comemorar a passagem do século e do milênio, esta edição especial, sob a organização de André Green, reuniu psicanalistas de diversas partes do mundo. A questão fundamental que norteou a temática emergiu da preocupação com a fragmentação do corpo teórico e com a multiplicidade de tendências representadas pelas diversas formas de enfocar a psicanálise contemporânea. Em decorrência disto, aflorou uma pergunta fundamental: "continuidade a qual Freud e a qual momento de seu pensamento? O viés adotado para estabelecer a interlocução, tendo em conta este questionamento, foi o de analisar o processo de constituição da ética, partindo da transcrição da physis em ethos, a fim de estabelecer uma analogia com ideias utilizadas por Freud para apresentar a psicanálise como um campo inédito. E, assim, pensarmos um trilhamento pela mensagem freudiana.
\end{abstract}

Palavras-chave: Psicanálise. Freud. Ética.

Abstract: In this article it is aimed to establish an interlocution between ethics and psychoanalysis, based on the thematic presented in the special edition of the French Journal of Psychoanalysis. With the objective of commemorating the passage of the century and the millennium, this special edition under the organization of André Green, joined psychoanalysts of diverse parts of the world. The fundamental question that guided the thematic emerged on the concern about the fragmentation of the theoretical body and with the multiplicity of trends represented for the diverse forms to focus the contemporary psychoanalysis. In result of this, a fundamental question arose, "is this continuity to which Freud and to which moment of his thought?" The adopted line to establish the interlocution, considering this questioning, was to analyze the process of constitution of the ethics, based on the transcription of physis in ethos, in order to establish an analogy with ideas used by Freud to present the psychoanalysis as an unknown field. And thus, to think about a route by the Freudian message.

Keywords: Psychoanalysis. Freud. Ethics.

$* * * * * * * * * * * * * * * * * * * * * * * * * *$

Na recente passagem do século e do milênio, nós nos deparamos com diversas publicações suscitadas por questionamentos e por reflexões sobre o desenvolvimento da produção de nossos conhecimentos. Dentre essas publicações encontramos a Revista Francesa de Psicanálise que, para comemorar a passagem do milênio, publicou uma edição especial, reunindo psicanalistas de diversas partes do mundo. A temática comum foi refletir sobre a mensagem freudiana e sua continuidade. A

\footnotetext{
${ }^{1} \mathrm{O}$ presente texto corresponde a uma segunda versão modificada do artigo homônimo publicado na Revista Tempo da Ciência, v. 16, p. 175-184, 2009.

${ }^{2}$ Psicólogo clínico formado pela UEM e professor do Curso de Filosofia da UNIOESTE. Realizou mestrado pela Universidad Complutense de Madri e mestrado pelo Programa de Pós-Graduação em Filosofia pela UNIOESTE. E-mail: rjperin@gmail.com
} 
pergunta fundamental foi: - Continuidade a qual Freud e a qual momento do seu pensamento?

André Green assumiu a incumbência de organizar esse número especial da revista. Na argumentação para fundamentar tal temática, emergiu a preocupação

[...] com a fragmentação do corpo teórico da disciplina e com a multiplicidade de tendências representadas por diversos autores da psicanálise contemporânea. A situação se tornou tão preocupante, que a comissão de programa do Congresso da Associação Psicanalítica Internacional, ocorrido, em Nice, em 2001, sentiu necessidade de submeter à nossa reflexão um questionamento tão geral quanto possível sobre o que é a psicanálise. Poderíamos nos surpreender ao nos vermos obrigados a retomar definições de base que deveriam estar solidificadas mais de cem anos após o nascimento da psicanálise. (GREEN, 2001, p. 17).

Do conjunto de artigos apresentados pelos psicanalistas aflorou uma questão apontada pela imensa maioria: a experiência da psicanálise é a experiência da clínica da cura. Há, porém, variações no modo de entender essa questão. André Green identificou três correntes: 1) uma visão pragmática, enfocando a psicanálise como uma terapêutica que deve apresentar-se a partir de sua eficácia; 2) uma corrente que entende a experiência psicanalítica como o eixo fundamental para produzir pesquisas, pois a psicanálise não se identifica com nenhuma outra forma de saber; 3) uma tendência preocupada com a necessidade de a psicanálise refletir e explicitar seus fundamentos epistemológicos. Estas questões nos remetem às considerações feitas por Freud, em 1926, no texto Análise Profana: na psicanálise existiu, desde o começo, uma união indissolúvel entre curar e pesquisar. Decorre, portanto, que a prática clínica sempre serviu como um caminho (método) para pensar o encontro que possibilita a emergência dos sujeitos psíquicos. É através de uma práxis, de um encontro marcado por um agir próprio, que possibilita a manifestação e a compreensão desses sujeitos.

Para pensar os fundamentos desta práxis própria da psicanálise, no interior da universidade, que é um dos lugares onde se produz pesquisa, mas não a cura, é importante explicitar o que nos autoriza a tal empreendimento. Jean Laplanche, na introdução de seu livro Nuevos Fundamentos para el Psicoanálisis, apresenta a possibilidade de se pensar a experiência psicanalítica a partir de quatro lugares. $\mathrm{O}$ primeiro deles é o lugar privilegiado da cura psicanalítica. $\mathrm{O}$ autor destaca as duas especificidades fundamentais para entender a clínica psicanalítica. A primeira é que ela se produz em um marco fundador, cuja essência é a "regra fundamental", que encaminha um processo em ressonância com um processo fundador do ser humano. A segunda especificidade é que o

[...] objeto da psicanálise não é o objeto humano em geral [...], mas um objeto humano que é capaz de dar forma à sua experiência, e o 
faz essencialmente através da linguagem da cura. Assim, existe aí um movimento de manifestação de toda a sua vida. Uma epistemologia e uma teoria psicanalítica deve considerar, nos seus fundamentos, o fato de que o sujeito humano é um ser que teoriza, que teoriza a si mesmo (LAPLANCHE, 1987, p. 19-20).

Portanto, a ação de teorização de si mesmo supõe uma relação dual em que o elemento transferencial supõe a repetição da história constitutiva do sujeito humano com seu analista.

O segundo lugar e objeto da experiência psicanalítica foi denominado por Laplanche de psicanálise "extramuros", para substituir o termo de psicanálise aplicada; termo que pode produzir críticas por supor a pretensão de aplicar os conhecimentos da clínica psicanalítica aos outros campos do saber. O próprio Freud (1981) foi o pioneiro em praticar a psicanálise "extramuros", ao produzir textos como, por exemplo, Totem e Tabu, O Mal-Estar na Civilização, Moisés e o Monoteísmo. Assim, temos um movimento da psicanálise que vai ao encontro dos fenômenos culturais. Ou, como nos diz Renato Mezan, em sua tese doutoral, Freud Pensador da Cultura: "A psicanálise é em si mesma uma parte da cultura contemporânea, tanto no plano científico-filosófico, quanto no efeito imenso que as posições inspiradas direta ou indiretamente por Freud tiveram sobre os costumes e as ideias deste século" (MEZAN, 1985, p. 19).

O terceiro lugar seria a teoria como experiência. Aqui retornamos novamente a Freud como referência a esta forma de experiência. Escritos como, por exemplo, Além do Princípio do Prazer, apontam para uma experiência muito particular de Freud que ele mesmo denominou de especulação. Aqui a palavra especulação tem um sentido de inferir da práxis clínica pensamentos teóricos que se articulam com outras dimensões do saber ou que apontam para algo de novo, de um possível vislumbrar de algo que se desvela. A este episódio, André Green (2003) se referiu, em seu livro La Nueva Clínica Psicoanalítica y la Teoria de Freud, como "a virada dos anos loucos" ou "a virada de 1920". Essa virada tem, como pano de fundo, a Primeira Guerra Mundial, bem como dificuldades oriundas da própria prática clínica que precisavam de esclarecimento. É o que, por exemplo, ocorre com a tendência a repetir constantemente situações vividas, e revividas no processo transferencial, impedindo a evolução do paciente por conta de uma certa pulsão destrutiva. Esses termos usados por Green se referem ao impacto produzido entre os psicanalistas, devido a essas novas especulações, introduzindo conflitos, confrontando-os com novas escolhas de certos caminhos a trilhar. Essa nova perspectiva de experiência reforça a ideia de que toda verdadeira teorização é uma experiência que compromete o pesquisador.

O quarto lugar é a história como lugar e objeto da experiência. Para Laplanche, lhe "[...] interessa a história de um pensamento inteiramente movido pelo seu objeto ou, se vocês preferirem, inteiramente movido pela sua pulsão". (LAPLANCHE, 1987, 
p. 24). Neste sentido, a história da psicanálise e, especificamente, o pensamento freudiano, nos mostram a riqueza da emergência do elemento pulsional inconsciente como princípio de movimento da produção teórica e objeto da própria psicanálise. E, justamente, é a história como um lugar de experiência conflitiva que aflora como um dos aspectos apresentados pela Revista Francesa de Psicanálise, quando propõe a pergunta: - A qual Freud, a qual momento do seu pensamento trilhar?

Uma pesquisa tem por objetivo produzir uma teorização e, enquanto tal, ela compromete o pesquisador. Estamos, portanto, naquilo que Laplanche denominou como o terceiro e o quarto lugar da experiência psicanalítica: a teoria e a história em uma relação dialética onde aflora o essencial da psicanálise, a dimensão do desejo, o aflorar do inconsciente. É o que nos diz Renato Mezan (1985, p. 10):

[...] o que existe são problemas que, de uma forma ou de outra, dizem respeito ao investigador, fazem parte de suas inquietações e proporcionam um certo prazer ao serem abordados. O desejo de 'resolver um problema', ou seja, de vencer uma dificuldade, de lançar luz sobre um domínio até então confuso ou inexplorado, está sempre presente, em toda atividade intelectual. O que se passa é que este desejo não ousa dizer seu nome [...]. Não é possível aventurar-se pelos domínios da psicanálise fingindo ignorar que os temas a serem tratados dizem respeito, também exemplarmente, ao investigador $\mathrm{e}$ às suas motivações.

É isto o que nos autoriza, no âmbito da universidade, a procurar estabelecer uma interlocução com a psicanálise. O viés adotado será o de analisar o processo de constituição da ética, a partir do modo de transcrição da physis em ethos, a fim de estabelecer uma analogia com ideias utilizadas por Freud para apresentar a psicanálise como um campo inédito. E, assim, pensarmos um trilhamento pela mensagem freudiana.

Começar uma reflexão sobre a ética, partindo de um enfoque da fenomenologia do ethos requer, inicialmente, algumas justificativas. Esta escolha, primeiramente, é uma homenagem e um reconhecimento ao filósofo e mestre Henrique C. de Lima Vaz. Em seu livro, Escritos de Filosofia II: ética e cultura, Lima Vaz parte daquilo que denominou de fenomenologia do ethos, para refletir sobre o intrincado problema do nascedouro da ética na cultura ocidental. Ao tomar esse caminho, ele faz um percurso de volta às origens da ética, visando a mostrar toda a riqueza do movimento presente no pensamento grego. Assim, evidencia-se a dimensão do mestre, característica ímpar do filósofo, a quem tomaremos como uma das referências para fundamentar a presente reflexão sobre a ética.

Este movimento, presente no pensar grego, nos remete à questão daquilo que se manifesta, o fenômeno. A maneira essencial para captar e interpretar aquilo que aparece e se mostra, ocorre pela via da razão (logos), fruto da experiência originária feita na Grécia clássica. Logos é, justamente, o discurso que possibilita o ver; é o que 
deixa e, ao mesmo tempo, faz ver, e, portanto, uma maneira de concatenação e de recolher o dado. Esta é a segunda justificativa, a questão do fenômeno como logos, quer dizer, a fenomenologia como método de investigação.

José Luis Aranguren, filósofo espanhol, em seu livro Ética, ao apresentar o princípio etimológico como uma das vias possíveis para fundamentá-la, enfatiza a importância da filologia. Para Aranguren, o filósofo não deve contentar-se em ser amigo da razão argumentativa, mas deve, também, ser amigo das palavras. E acrescenta, "[...] a etimologia nos devolve a força elementar das palavras originárias, gasta com o longo uso, às quais é imprescindível voltar para recuperar seu sentido autêntico, a arkhé". (ARANGUREN, 1968, p. 22). Recuperar o sentido autêntico das palavras é como procurar reconstruir uma peça em seu aspecto (eidos) original. É um trabalho de "arqueologia".

Uma destas palavras originárias é o termo grego ethos, o qual nos permite ver a força e o vigor daquilo que permanece na ética. Ou, como se diria em uma expressão heideggeriana, aquilo que "perdura e demora” na ética. A fenomenologia do ethos, em Lima Vaz, procura resgatar justo essa "arqueologia" no bojo do pensamento grego, sendo, portanto, amigo das palavras, philólogo. O vocábulo grego ethos, assim como o vocábulo physis, são duas formas primeiras de manifestação do ser ou de sua presença. Portanto, o ethos nada mais é do que a transcrição da physis que ocorre através da ação humana engendrando as estruturas histórico-sociais. Ethos possui dois sentidos fundamentais. Bem observa Lima Vaz (1988, p. 12-13):

A primeira acepção de ethos (eta inicial) designa a morada do homem (e do animal em geral). O ethos é a casa do homem. O homem habita sobre a terra acolhendo-se ao recesso seguro do ethos. Este sentido de um lugar de estada permanente e habitual, de um abrigo protetor, constitui a raiz semântica que dá origem à significação de ethos como costume, esquema praxeológico durável, estilo de vida e ação.

Continua, ainda, Lima Vaz (1988, p. 14): “A segunda acepção do ethos (com épsilon inicial) diz respeito ao comportamento que resulta de um repetir-se dos mesmos atos. É, portanto, o que ocorre frequentemente ou quase sempre (pollakis), mas não sempre (aei), nem em virtude de uma necessidade natural. Daqui a oposição entre éthei e phisei, o habitual e o natural". Assim, percebemos que, ao concebermos o ethos desta forma, estamos designando a formação do hábito, pois ele se constitui pela repetição, mas, a completude do hábito ocorre pela incorporação de um determinado estado de coisas que passa a fazer parte da constituição do agente. Ora, essa ideia de estado ou de constituição tem sua origem no termo grego échein, do qual se origina hexis. O vocábulo hexis tem por significado a possessão estável de uma determinada maneira de ser, que ocorre através da escolha e da deliberação do agente, o que determina uma característica de repetição, o hábito. Desse modo, o hábito é 
um ethos-hexis, significando a possibilidade de o sujeito apropriar-se de si mesmo, expressando a sua autonomia e, portanto, seu caráter. Temos, pois, que o

[...] ethos como costume, ou como realidade histórico-social, é princípio e norma dos atos que irão plasmar o ethos como hábito (ethos-hexis). Há, pois, uma circularidade entre os três momentos: costume (ethos), ação (práxis), hábito (ethos-hexis), na medida em que o costume é fonte das ações tidas como éticas e a repetição dessas ações acaba por plasmar os hábitos. A práxis, por sua vez, é mediadora entre os momentos constitutivos do ethos como costume e hábito, em um ir e vir que se descreve exatamente como um círculo dialético: a universalidade abstrata do ethos como costume inscrevese na particularidade da práxis como vontade subjetiva, e é universalidade concreta ou singularidade do sujeito ético no ethos como hábito ou virtude. (LIMA VAZ, 1988, p. 15).

Todo este processo aponta para a dimensão da tradição tendo como horizonte a perspectiva da produção da cultura. Isso implica pensar o ethos social ou, se quisermos, o ethos cultural, como o espaço possível à compreensão e à expressão do ser do homem. A articulação ethos-cultura põe, em destaque, a natureza axiogênica da ação humana, significando que é através dela que o homem cria o mundo como um universo de formas simbólicas, na medida em que é produtora de significação e, desta forma, constrói sua morada. Volta a frisar Lima Vaz (1988, p. 38): "É, pois, a partir da própria origem do universo das formas simbólicas que se desdobra a dimensão do ethos: o homem habita o símbolo e é exatamente como métron, como medida ou norma que o símbolo é ethos, é morada do homem".

Em Heidegger, a expressão "ethos como a morada do homem" vai aparecer com toda a sua força reflexiva no texto Carta sobre o Humanismo. Começa o texto dizendo: "Estamos ainda longe de pensar, com suficiente radicalidade, a essência do agir" (HEIDEGGER, 1979a, p. 149). E, em seguida, diz que "a essência do agir é o consumar". O consumar é a possibilidade de alguma coisa manifestar-se na plenitude de sua essência; naquilo que já é. "Porém, antes de tudo, aquilo que 'é' é o ser" (HEIDEGGER, 1979a, p. 149). E o que vai possibilitar a consumação da relação do ser com a essência do homem é o pensar. Assim, o pensar abre caminho para entender a manifestação que ocorre nesse movimento do vir a ser. É a possibilidade de abertura que ocorre, segundo Heidegger, pela via da linguagem. "Se deve pensar a essência da linguagem a partir da correspondência com o ser, concretamente como tal correspondência mesma, isto é, como morada do ser humano". (HEIDEGGER, 2001, p. 274). Mais: "Linguagem é o advento do ser que se revela e se oculta" (HEIDEGGER, 2001, p. 269). Portanto, "o único que importa é que a verdade do ser chegue à linguagem e que o pensar alcance dita linguagem". (HEIDEGGER, 2001, p. 269).

Aqui, aparecem conceitos fundamentais do pensamento heideggeriano que comandam a sua interrogação e alimenta sua reflexão. O principal deles é a ideia do 
movimento estabelecido entre presença e ausência; ou a ideia de velamento e de desvelamento do ser como forma de pensar a temática da verdade. Este pensamento articula Heidegger à toda a tradição filosófica que pergunta pela verdade do ser, tendo um dos paradigmas do ser a physis

Diz-nos Ernildo Stein, em seu livro Compreensão e Finitude: estrutura e movimento da interrogação heideggeriana: "Heidegger resume numa palavra a unidade de seu pensamento, a constância de seu caminho e a inspiração do objeto: é a alethia (STEIN, 2001, p. 55). Reforça ainda o intérprete: "Se a aletheia resume o pensamento de Heidegger é devido ao fato de nele eclodir, novamente, na história da filosofia, aquilo que estava impensado, mas que comanda o movimento da tradição em suas máximas possibilidades" (STEIN, 2001, p. 79). É, justamente, este velamento / desvelamento, presente no pensar dos primeiros filósofos, que Heidegger procura resgatar e que a metafísica, ao introduzir o esquema mental centrado na relação sujeito-objeto, não permite captar. Como observa, mais uma vez, Stein (2001, p. 82):

Aquilo que se retrai, sendo, contudo, a abertura, esconde-se como fundamento da relação sujeito-objeto, é a aletheia pensada em sua verdadeira essência, pois, a aletheia sustenta a presença em que se confrontam o eu e o objeto. Pensando como aletheia, o ser adquire sua dimensão ocultante - desocultante que se manifesta ativadora da presença.

Esta manifestação ativadora da presença é a própria essência da physis. Por isto, O filósofo alemão vai nos dizer, no final do texto Sobre a Essência da Physis em Aristóteles:

Ser é o desocultar que se oculta: physis em um sentido inicial. $\mathrm{O}$ desvelar-se é um surgir ao desocultamento, isto é, desocultamento significa $a$-letheia: a verdade. A verdade, como nós a traduzimos, não é essencialmente um caráter do conhecimento humano e de seus enunciados; tampouco é um valor ou uma "ideia" cuja realização, sem que saibamos muito bem por quê, o homem deve aspirar, mas a verdade pertence, enquanto desocultar-se, ao ser mesmo: physis é aletheia (HEIDEGGER, 200o, p. 248).

Percebemos, portanto, no pensamento heideggeriano, uma volta às origens do pensamento grego, porém, mostrando o impensado na transcrição da physis em ethos pela via do logos (linguagem).

Em seu livro Palavra e Verdade: na filosofia antiga e na psicanálise, Luiz Alfredo Garcia-Roza nos diz:

Aquilo que Freud nos mostrou desde seus primeiros escritos é que na prática psicanalítica a verdade se insinua não a partir do caráter formalizado do discurso, mas, precisamente, quando o discurso falha, quando é atropelado e violentado por um outro discurso que provoca, 
no primeiro, lacunas, os não tão adequadamente denominados atos falhos. (GARCIA-ROZA, 2005, p. 20).

Assim, temos, de entrada, a questão de que a prática psicanalítica tem uma preocupação com a verdade. Do ponto de vista da tradição filosófica, diz-nos Heidegger no texto Sobre a Essência da Verdade: “[...] verdade é a adequação da coisa com o conhecimento. Mas pode se entender também assim: Verdade é a adequação do conhecimento com a coisa” (HEIDEGGER, 1979b, p. 133). Portanto, se a prática psicanalítica tem uma preocupação com a verdade, é necessário colocar, em questão, a ideia de concordância para situá-la na perspectiva do desvelamento. É isto o que Freud fez, quando passou a pensar a origem da neurose não mais causada por um episódio de abuso sexual concreto perpetrado pelo pai, a ponto de dizer para seu amigo Fliess, em uma carta de 21 de setembro de 1897, "[...] não acredito mais em minha neurótica (teoria das neuroses)" (FREUD apud MASSON, 1986, p. 265). E acrescenta como um dos argumentos: "o conhecimento seguro de que não há indicações de realidade no inconsciente, de modo que não se pode distinguir entre verdade e a ficção". (FREUD apud MASSON, 1986, p. 265-266).

Portanto, temos, aí, um momento marcante na gênese da psicanálise, que desloca a dimensão da verdade da concordância para a verdade enquanto desvelamento, aletheia. E isso, de tal modo que aquilo que se insinua, aquilo que se manifesta pela palavra na prática da clínica psicanalítica aponta para algo do imaginário e da fantasia. O movimento, todavia, que produz esse discurso é da ordem do manifesto que procura pelo desvelamento e, portanto, aponta para a verdade e, assim, possibilita a emergência desse imaginário e dessa fantasia como algo que se manifesta aí. Existe um movimento que faz emergir algo que se desvela e que se nomeia como manifestação do desejo. É a possibilidade do outro discurso, aquele que não se restringe à verdade da concordância, mas à verdade do apresentar-se de algo que habita o ser e o revela, ou melhor, o desvela. Nesse sentido, podemos nos aventurar a dizer que physis e aletheia fazem sua emergência enquanto ethos, quer dizer, enquanto aquilo que habita o sujeito psíquico.

Pensando a psicanálise por este viés, nós nos deparamos com algumas questões que precisam ser explicitadas. A primeira delas nos reporta ao próprio Freud que, em 1923, apresentou uma definição da psicanálise, em um texto escrito para uma enciclopédia, com o título Dois Artigos para a Enciclopédia. Ali nos apresenta primeiramente a psicanálise como um método (caminho) para investigar processos anímicos dificilmente acessíveis de outra forma. Aqui estamos no primeiro lugar da experiência psicanalítica apresentada como concordância pela imensa maioria dos psicanalistas participantes da edição especial da Revista Francesa de Psicanalise: a experiência da cura psicanalítica. É a que introduz o ser humano para a abertura de manifestar-se pela linguagem da cura, podendo apropriar-se daquilo que o habita de maneira inconsciente. Na fenomenologia do ethos, apresentada em Lima Vaz, é o que 
é denominado de ethos-hexis; porém é um apropriar-se que ocorre pela via da decisão e da escolha, mas que possibilita vislumbrar o inédito da psicanálise quando circunscreve a razão à dimensão do desejo, cuja manifestação se faz pelo outro discurso. Ao se comprometer com seu desejo, o sujeito tem a possibilidade de desvelar-se no processo de pensar a si mesmo ou, como diz Laplanche, de autoteorizar-se.

Ainda na referida definição sobre a psicanálise feita por Freud, temos a teoria como um dos modos de entendê-la e, como vimos em Mezan, tal teoria compromete o pesquisador com seu desejo e suas motivações. Quando nos deparamos com conflitos como os apresentados pelos psicanalistas na Revista Francesa de Psicanálise, então nos ocorre perguntar: - Os diferentes pontos de vista, que perguntam sobre que momento do pensamento de Freud seguir, conseguem explicitar os desejos que os mobilizam?

Ora, uma pista segura nos é apresentada por Freud quando apresenta o outro discurso como possibilidade de desvelamento do velamento, ou seja, aquilo que faz parte da essência da manifestação do ser, cuja origem está no movimento do existir que nos coloca em uma relação com o outro, a ponto de que aquilo que nos é familiar transforma-se em não familiar (Unheimlich). Quando pensamos a experiência psicanalítica apenas do ponto de vista da clínica da cura, ficamos esvaziados para pensar o conflito no interior do movimento psicanalítico como a emergência do outro discurso.

Portanto, o terceiro e o quarto lugar da experiência psicanalítica, enfocados a partir de Laplanche, ficam alijados do trilhamento originário e original efetuado por Freud para apresentar o inédito da psicanálise como método de investigação de processos anímicos inacessíveis de outra forma. Assim, é fundamental ter presente o movimento engendrado pelo desejo, cujo trilhamento é o que possibilita a constituição do sujeito psíquico e que tem possibilidade de apropriar-se de si mesmo por meio da experiência psicanalítica pela auto-teorizacão. É o trilhamento de um caminho do apresentar-se do ausentar-se que retrocede sobre si mesmo, mas é um abrir-se pela repetição, através da via da linguagem no processo de transferência. Ou seja, é um modelo de transcrição da physis em ethos e, enquanto tal, é aletheia.

\section{Referências}

ARANGUREN, J. L. “Ética”. In: Editorial Revista de Occidente: Madrid, 1968.

FIGUEIREDO, L. C. Escutar, recordar, dizer: encontros heideggerianos com a clínica psicanalítica. São Paulo: Educ / Escuta, 1994.

FREUD, S. Obras completas - 3 tomos. 4. ed. Madrid: Biblioteca Nueva, 1981.

. "Correspondências". In: MASSON, J. M. A correspondência completa de Sigmund Freud para Wilhelm Fliess — 1887-1904. Trad. Vera Ribeiro. Rio de Janeiro: Imago, 1986. 
GARCIA-ROZA, L. A. Palavra e verdade: na filosofia antiga e na psicanálise. 5. ed. Rio de Janeiro: Zahar, 2005.

GREEN, A. (Org.). La nueva clínica psicoanalítica y la teoría de Freud: aspectos fundamentales de la locura privada. Buenos Aires: Amorrortu, 2001.

. "Psicanálise contemporânea". In: Revista Francesa de Psicanálise. Rio de Janeiro:

Imago, 2003.

HEIDEGGER, M. "Sobre o humanismo". In: Conferências e escritos filosóficos. Trad., introd., notas de E. Stein. São Paulo: Abril Cultural, 1979a (Coleção Os Pensadores).

. "Sobre a essência da verdade". In: Conferências e escritos filosóficos. Trad., introd., notas de E. Stein. São Paulo: Abril Cultural, 1979b (Coleção Os Pensadores).

. Hitos. Madrid: Alianza, 2000.

. A caminho da linguagem. Trad. M. S. Cavalcanti. Petrópolis, RJ: Vozes, 2003.

LAPLANCHE, J. Nuevos fundamentos para el psicoanálisis. Buenos Aires: Amorrortu, 1987.

LIMA VAZ, H. C. de. Escritos de filosofia II: ética e cultura. São Paulo: Loyola, 1988.

MEZAN, R. Freud, pensador da cultura. São Paulo: Brasiliense, 1985.

STEIN, E. Compreensão e finitude: estrutura e movimento da interrogação heideggeriana. Ijuí, RS: Editora Unijuí, 2001. 